\title{
New therapeutic approaches in the treatment of node-positive cervical cancer patients based on molecular targets: a systematic review
}

\author{
Marcin Sniadecki ${ }^{1}$, Anna Swierzko ${ }^{2}$, Mateusz Dabkowski ${ }^{3}$, Marzenna Orlowska-Volk ${ }^{4}$, \\ Ewa Wycinka ${ }^{5}$, Dagmara Klasa-Mazurkiewicz ${ }^{6}$, Agnieszka Milewska ${ }^{7}$, Patryk Poniewierza $^{8}$, \\ Marcin Liro ${ }^{1}$, Dariusz Wydra ${ }^{1}$ \\ ${ }^{1}$ Department of Gynecology, Gynecologic Oncology and Gynecologic Endocrinology, Medical University of Gdansk, \\ Gdansk, Poland \\ ${ }^{2}$ Polish Academy of Sciences, Institute for Medical Biology, Lodz, Poland \\ ${ }^{3}$ M. Sklodowska-Curie Institute — Oncology Center, Brachytherapy Facility, Warsaw, Poland \\ ${ }^{4}$ MVZ Clotten, Freiburg im Breisgau, Germany \\ ${ }^{5}$ Department of Statistics, Faculty of Management, Gdansk University, Sopot, Poland \\ ${ }^{6}$ Medical University of Gdansk, Gdansk, Poland \\ ${ }^{7}$ Main Library, Medical University of Gdansk, Gdansk, Poland \\ ${ }^{8}$ Department of Gynecology and Obstetrics SPS ZOZ, Lebork, Poland
}

\begin{abstract}
Cervical uterine cancer is the second most frequent female cancer worldwide and a substantial burden for low-income societies and the patients themselves. Understanding the molecular mechanisms of metastasis permits the development of therapies that limit tumor progression, as well as providing health and social benefits. Pathomorphology is still the basis of research and a reference standard for molecular analysis. The aim of our study was to research and critically evaluate clinical trials that use new oncological approaches for node-positive cervical cancer to gain an insight into the molecular mechanisms of tumor metastasis. Inclusion criteria: node-positive disease at baseline; at least a first phase clinical study comprising adult female patients; novel clinical approach (e.g., radiotherapy, immunotherapy, targeted therapy, vaccines, radiosurgery); histologic measurement of treatment efficacy (preferably lymph node ultrastaging); and publications in English language only. Information sources: US Clinical trials registry, EU Clinical trials register, ISRCTN registry, and Ovid, EBSCO and Cochrane Collaboration databases. Access dates: from January 2010 to April 2018. Exclusions: Abstracts that did not meet the inclusion criteria or with unreliable data. We collected complete data (e.g., the entire publication associated with included abstracts, heterogeneity examination of individual studies, and validity measurement of the statistical methods used). Results were analyzed in relation to the most recent understanding of the pathogenesis of cervical cancer metastasis. We proposed a possible direction for drug treatment of epithelial tumors based on the mechanisms of metastasis. Key words: cervical cancer; lymph node; metastasis; trial; treatment; molecular; review
\end{abstract}

Ginekologia Polska 2019; 90, 6: 336-345

\section{INTRODUCTION}

Cervical cancer (CC) is the second most common female cancer with around 0.5 million cases worldwide and an annual upward trend of $0.6 \%$. The median age of death is 55 years. CC disproportionately afflicts women in low-resource nations where they do not receive adequate screening or therapy. The incidence varies from as high as $100 / 100000$ in unscreened populations to $1-5 / 100000$ in the highly screened populations of high-income countries [1].

Because a substantial proportion of patients in high-income countries will soon be in the preinvasive stage of CC, the main effort should be focused on possible therapies 
in patients with higher-stage cancers. The clinical factors that influence the prognosis for invasive cervical squamous carcinoma, the most common CC subtype, are stage of disease, age of patient, depth of invasion, volume of tumor, and lymphatic or vascular invasion; all of which correlate with the risk of lymph node metastasis (LNM) and systemic spread [1,2].

Understanding the molecular mechanisms of metastasis onset permits the development of therapies that limit tumor progression. Pathomorphology is still the basis of research and a reference standard for molecular analysis.

Patients with LNM are candidates for expensive and toxic methods of adjuvant treatments. The main treatment modality is cisplatin-based chemotherapy, which is an alkylating-like agent that damages the DNA repair process, as well as sensitizing CC tissue to radiotherapy [3,4]. Our study seeks to identify newly-available or recently-identified therapies indicated in scientific studies.

\section{Objectives}

The aim of our study was to research and critically evaluate recent clinical trials of treatment modalities in patients with node-positive CC (NPCC) and to identify effective therapies to date. We also focused our analysis on the molecular mechanisms of tumor metastasis and current directions in developing new therapies.

\section{MATERIAL AND METHODS}

\section{Studies Eligibility and Treatment Selection}

The material of this review consisted of completed clinical studies (clinical trials with published results) concerning not-yet standard methods of treatment (or their novel combinations) for patients with NPCC, irrespective of their International Federation of Gynecology and Obstetrics (FIGO) stage (2009-2018). Only those abstracts of trials and completed English language studies, that were reported between January 2010 and April 2018 ( $1^{\text {st }}$ - to $4^{\text {th }}$-phase trials that were ongoing, or finished, or interrupted due to unfavourable outcomes) were considered for further evaluation.

The exclusion criteria were a standard treatment protocol (defined as "platinum-based chemotherapy"), conventional radiation (brachytherapy, intensity modulated radiotherapy, teletherapy, other approaches of classical radiation methods), and other drug therapies and treatment schedules as recommended by the National Comprehensive Cancer Network (NCCN) for an adjuvant, second-line therapy or metastatic setting [5]. Our information sources were the US Clinical Trials Registry, the EU Clinical Trials Register, the ISRCTN Registry, and the Ovid, EBSCO and Cochrane Collaboration databases. Where possible, the reference standard for each study protocol that we selected, was a histologic finding confirming lymph node-positive disease, and in the remaining cases, positive lymph nodes were identified by imaging techniques. We selected those studies that met our eligibility criteria for analysis and the results are shown in Table 1, providing information on study phase, level of evidence, FIGO stage, recruitment period, type of treatment, outcome measures, and results. In addition, we conducted a subjective literature research to identify other factors affecting lymph node metastasis in CC that could be targets for therapy in the near future.

\section{Statistical analysis}

Metadata analysis tools were not applied because heterogeneity of the selected studies was too high. However, it was possible to combine issues that were relevant for metadata analysis. These are shown in Table 2 in the Results section. We used "Strengthening the reporting of observational studies in epidemiology" (STROBE) as a guide to writing the review section of our study [6]. In the systematic review we report here, the aggregate data (no individual patient data was used) was compared without violating the rights of any third parties.

\section{RESULTS}

Eight clinical trials met our further comparative assessment selection criteria, from a total of 911 studies that met our entry criteria (Fig. 1 and Tab. 1) [7-14]. Two randomized controlled trials (RCT) were identified $[12,14]$. Three of the eight studies were ultimately ruled out of our final selection, because they investigated the treatment impact of including paraaortic lymph nodes in the irradiation area. This therapy is the standard option for radiotherapy in cases of CC, although there is no high-quality data proving the validity of this procedure. These three excluded articles are listed in Appendix A. Further literature search revealed three relevant studies pertaining to novel therapeutic approaches in NPCC patients [10, 11, 13].

As mentioned above in the Methods section, the too-high heterogeneity of the study material meant that metadata analysis was not possible; however, Table 2 shows the selected issues that we were able to prepare for metadata analysis.

\section{DISCUSSION}

The purpose of our review was to research and critically evaluate the results of published scientific clinical studies of the past decade, on treatment approaches with advanced, node-positive cervical cancer patients. Our additional focus was to identify the most promising modalities of treatment that are based on the molecular mechanisms of CC metastasis. We were particularly interested in learning whether there are yet unknown metastatic mechanisms of, for example, 


\begin{tabular}{|c|c|c|c|c|c|c|c|c|}
\hline No & Study phase & LoE $^{1}$ & FIGO Stage ${ }^{2}$ & $\begin{array}{c}\text { Study } \\
\text { participants }\end{array}$ & $\begin{array}{l}\text { Recruitment } \\
\text { period }\end{array}$ & Drug or treatment & Main conclusion & Reference \\
\hline 1. & II & $\|$ & $\begin{array}{l}\text { Not given } \\
\text { (advanced, } \\
\text { persistent, } \\
\text { recurrent) }\end{array}$ & 69 & 2004-2008 & $\begin{array}{l}\text { cisplatin plus } \\
\text { cetuximab }\end{array}$ & $\begin{array}{l}\text { No additional } \\
\text { benefit of cetuximab } \\
\text { beyond cisplatin }\end{array}$ & $\begin{array}{l}\text { Farley et al. } \\
\text { (2011) [7] }\end{array}$ \\
\hline 2. & II & III & IB2-IVB & 25 & 2006-2011 & $\begin{array}{l}\text { Multimodal: triapine } \\
\text { plus cisplatin during } \\
\text { pelvic radiation } \\
\text { therapy with boost } \\
\text { and intracavitary } \\
\text { brachytherapy }\end{array}$ & $\begin{array}{l}\text { High rates of clinical } \\
\text { and metabolic } \\
\text { responses by adding } \\
\text { 3-AP to cisplatin; } \\
\text { promising results } \\
\text { put into randomized } \\
\text { clinical trial* }\end{array}$ & $\begin{array}{l}\text { Kunos et al. } \\
\text { (2014) [8] }\end{array}$ \\
\hline 3. & NA & III & IV & 9 & $2012-2014$ & $\begin{array}{l}\text { Adoptive T-cell } \\
\text { therapy } \\
(\text { HPV-TILs) })^{ \pm} \text {after } \\
\text { primary therapy }\end{array}$ & $\begin{array}{l}\text { Uncertain clinical } \\
\text { benefit }\end{array}$ & $\begin{array}{l}\text { Stevanović et } \\
\text { al. (2015) [9] }\end{array}$ \\
\hline 4. & $\begin{array}{l}\text { Ib (sub-study of } \\
\text { KEYNOTE-028 } \\
\text { trial) }\end{array}$ & III & $\begin{array}{l}\text { Not-specified } \\
\text { (advanced- } \\
\text { recurrent, } \\
\text { metastatic, } \\
\text { PD-L1 positive }{ }^{\ddagger} \text { ) }\end{array}$ & 24 & 2014-2018 & Pembrolizumab & $\begin{array}{c}\text { Partial response } \\
\text { in } 17 \% \text { patients, } \\
5 \text { patients with } \\
\text { grade } 3 \text { adverse } \\
\text { events (AEs), } \\
\text { no grade } 4 \text { AEs }\end{array}$ & $\begin{array}{l}\text { Frenel et al. } \\
2017 \text { [10] }\end{array}$ \\
\hline 5. & $\|$ & III & IIB-IVA & 19 & $2007-2008$ & Sunitinib & $\begin{array}{l}\text { Stable disease } \\
\text { in } 84 \% \text { patients }\end{array}$ & $\begin{array}{l}\text { Mackay et al. } \\
2010[11]\end{array}$ \\
\hline 6. & II & ॥ & IVB & 228 & 2008-2011 & $\begin{array}{l}\text { Pazopanib } \\
\text { plus lapatinib } \\
\text { or pazopanib } \\
\text { monotherapy } \\
\text { or lapatinib } \\
\text { monotherapy }\end{array}$ & $\begin{array}{c}78 \% \text { OS for } \\
\text { both arms of } \\
\text { monotherapy, for } \\
\text { pazopanib 49.7\%, } \\
\text { for lapatinib 44.1\% }\end{array}$ & $\begin{array}{l}\text { Monk et al. } \\
(2011)^{*}[12]\end{array}$ \\
\hline 7. & $\|$ & $\|$ & $\begin{array}{l}\text { Recurrent or } \\
\text { metastatic }\end{array}$ & 54 & 2008-2011 & $\begin{array}{l}\text { Pemetrexed plus } \\
\text { cisplatin }\end{array}$ & $\begin{array}{l}\text { Pemetrexed } \\
\text { plus cisplatin } \\
\text { is competing } \\
\text { to other regimen } \\
\text { in the treatment } \\
\text { of advanced, } \\
\text { persistent, } \\
\text { or recurrent CUC }\end{array}$ & $\begin{array}{c}\text { Miller et al. } \\
\text { [13] }\end{array}$ \\
\hline 8. & ॥ & III & $\begin{array}{l}\text { Recurrent or } \\
\text { metastatic }\end{array}$ & 69 & 2010-2012 & $\begin{array}{l}\text { Cediranib or } \\
\text { placebo plus } \\
\text { paclitaxel- } \\
\text { carboplatin } \\
\text { chemotherapy }\end{array}$ & $\begin{array}{l}1.4 \text { months in time } \\
\text { to progression } \\
\text { of experimental } \\
\text { vs. control arm }\end{array}$ & $\begin{array}{c}\text { Symonds et al. } \\
\text { (2015) [14] }\end{array}$ \\
\hline
\end{tabular}

${ }^{1}$ Level of Evidence, ${ }^{2}$ International Federation of Gynecology and Obstetrics; ${ }^{*}$ NCT01835171, •NA — not applicable ( \pm HPV-TILs $-\mathrm{T}$ cells selected for Human papilloma virus; +3 -aminopiridine-2-carboxylaldehyde thiosemicarbazone; ${ }^{\ddagger}$ PD-L1 - programmed death ligand 1

CC, that might permit both a better understanding of the biology of cancer and consequently, targeted therapies.

The histogenetic origin of all CC cases is from precancerous intraepithelial lesions. Histological variants depend in part on their location and their various known reactions to hormonal stimuli, and also partly in the variety of the activating gene combinations in virally-infected tissues that allows for progression from the preinvasive stage to the invasive disease. However, these "gene patterns" are not well researched [15]. Genetic profiles of CC (squamous- and adenocarcinomas) indicates positivity for high-risk types 16 and 18 of human papillomavirus (HPV), and co-expression of the $\mathrm{p} 16$ protein. The oncogene activation of the $\mathrm{p} 16$ gene is silenced by DNA methylation, turns the gene off, and places the developing cancer cells into "metastatic state". The over-expression of p53, in turn, is present in advanced cancers $[15,16]$. Patients with CC then face genetic susceptibility due to they cannot eliminate HPV because of their immunologic abnormalities. The literature also raises the issues of familial clustering, tobacco-related carcinogenesis and HPV infection, immunosuppression (transplantation, human immunodeficiency virus infection), human leukocyte antigen $[15,17]$.

From both the functional and ontogenetic points of view, CC is seen to spread in a complex network in various 


\begin{tabular}{|c|c|c|c|c|c|c|c|c|}
\hline 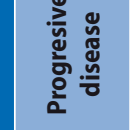 & 1 & 1 & 1 & 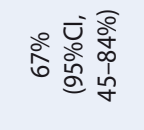 & 1 & ' & ओे & 1 \\
\hline 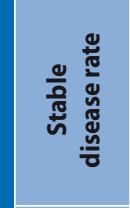 & : & i & i & 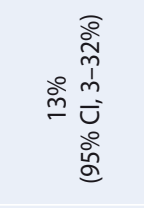 & 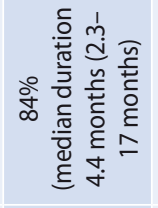 & ; & ஓे & ' \\
\hline 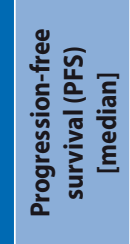 & 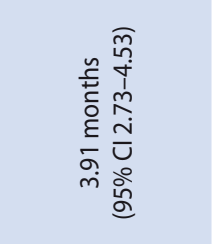 & 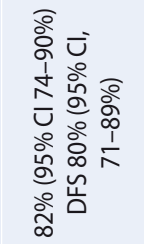 & i & 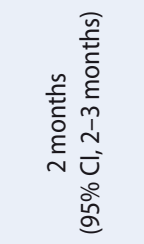 & 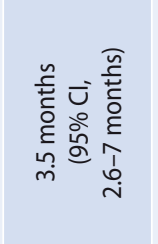 & 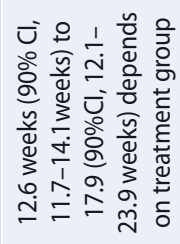 & 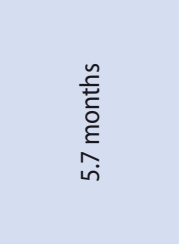 & 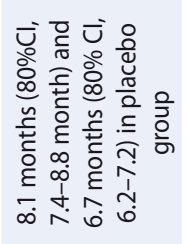 \\
\hline 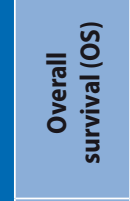 & 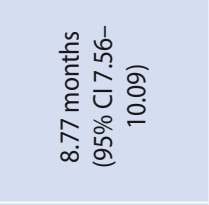 & i & ! & 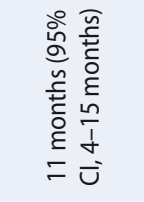 & i & 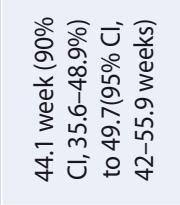 & 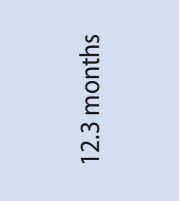 & i \\
\hline 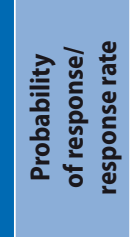 & 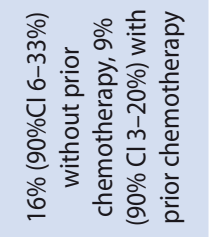 & 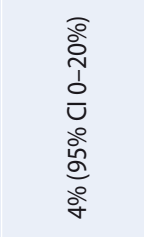 & 1 & 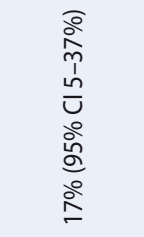 & 1 & 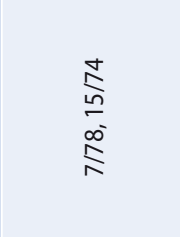 & 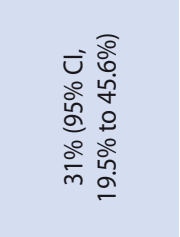 & 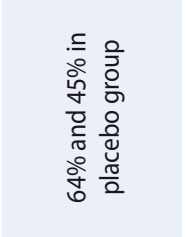 \\
\hline $\begin{array}{l}\frac{0}{3} \\
\frac{3}{3} \\
\frac{0}{0}\end{array}$ & : & i & 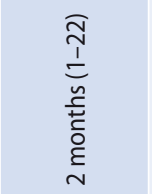 & 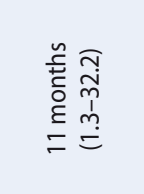 & ; & : & & 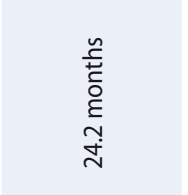 \\
\hline 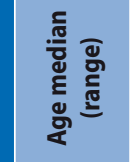 & $\begin{array}{c}\mathbb{T} \\
\frac{d}{d} \\
i\end{array}$ & $\begin{array}{l}\text { oo } \\
0 \\
1 \\
\tilde{m} \\
i n\end{array}$ & 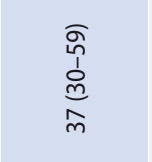 & 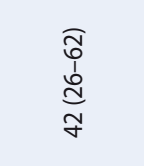 & 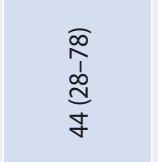 & 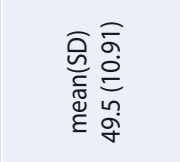 & $\begin{array}{l}\bar{o} \\
\hat{o} \\
\dot{\rho} \\
v \\
\dot{v}\end{array}$ & 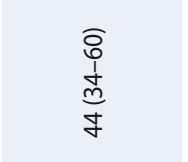 \\
\hline 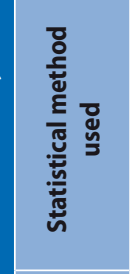 & 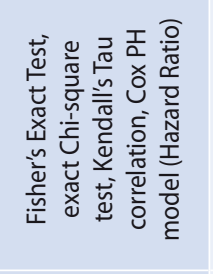 & 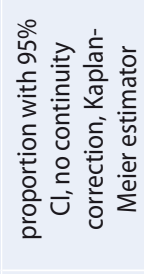 & 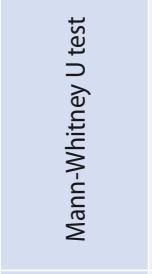 & 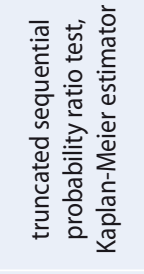 & 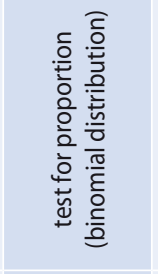 & 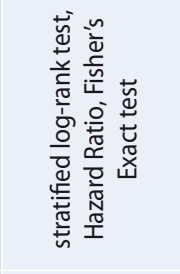 & 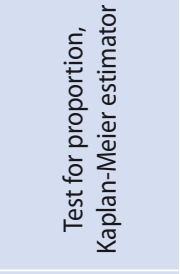 & 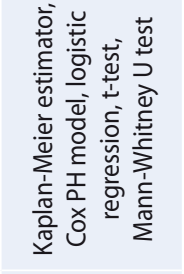 \\
\hline 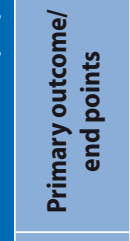 & 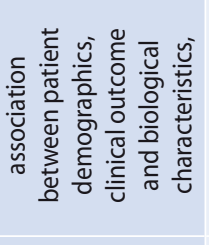 & 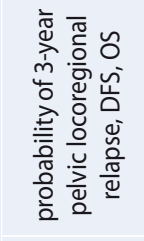 & 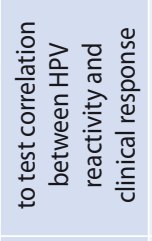 & 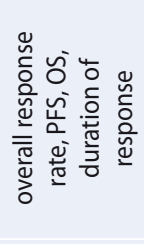 & 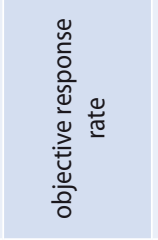 & 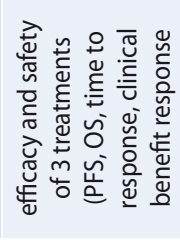 & 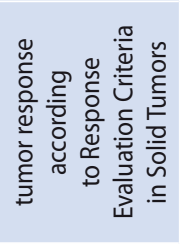 & $\begin{array}{l}\tilde{0} \\
\widetilde{u} \\
\underline{\alpha}\end{array}$ \\
\hline$=$ & 8ิ & $\stackrel{\sim}{\sim}$ & $a$ & $\stackrel{ \pm}{\sim}$ & g & $\stackrel{\infty}{\sim}$ & 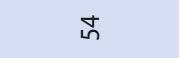 & 옹 \\
\hline 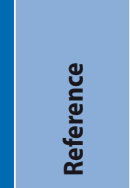 & 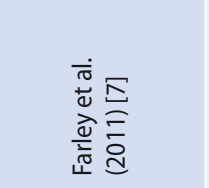 & 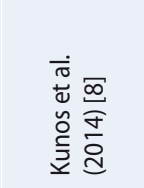 & 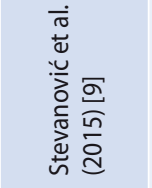 & 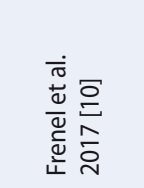 & 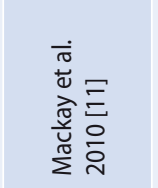 & 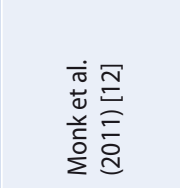 & 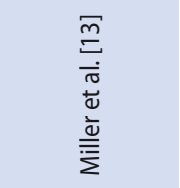 & 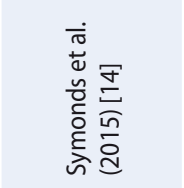 \\
\hline
\end{tabular}




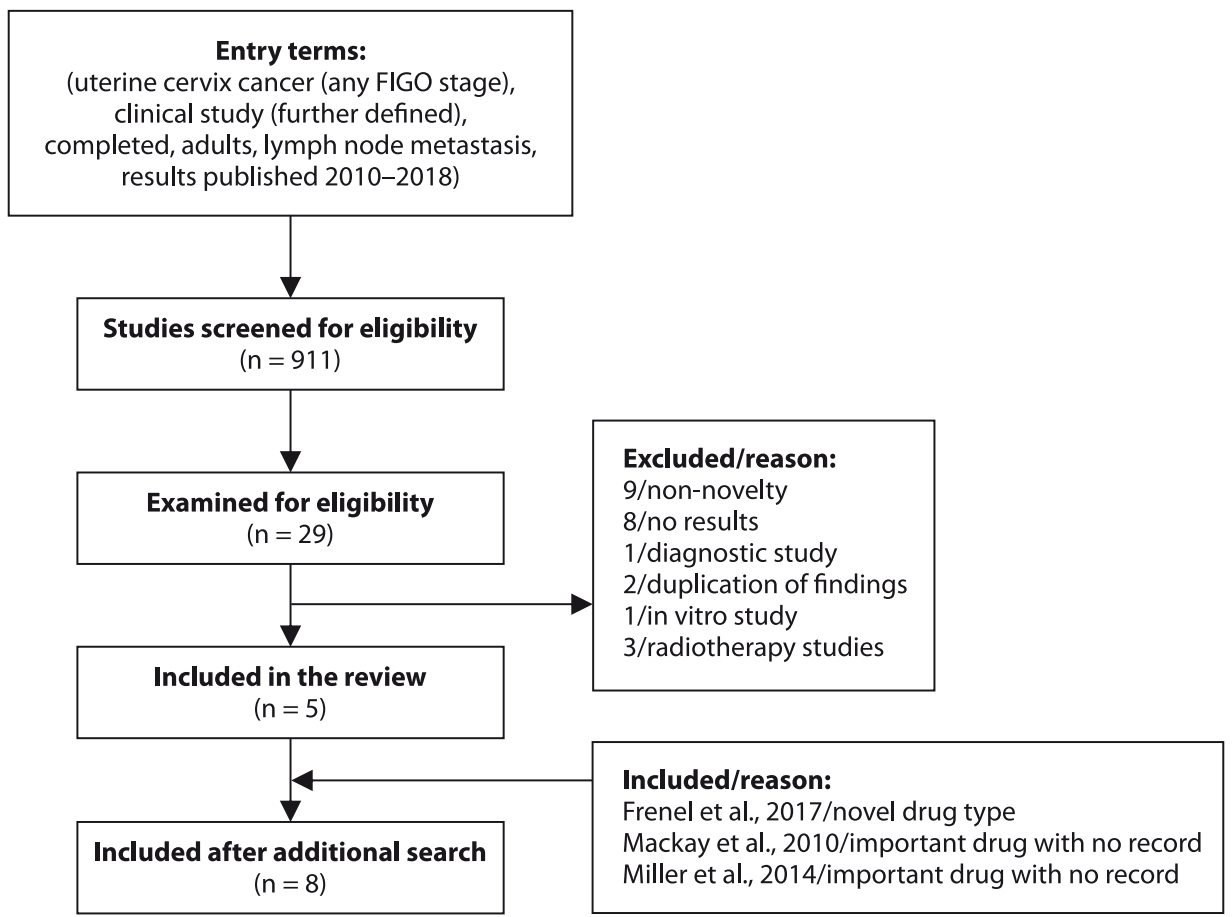

Figure 1. STROBE diagram presenting the process of selecting studies for analysis

directions, including into lymph vessels and nodes [18]. Furthermore, studies have confirmed that up to $25 \%$ of early CC cases result from primary sites of lymph node metastasis and also transport tumor cells into bone marrow $[19,20]$. These results form a prerequisite for improving our knowledge of the biological activity of the disease and its spreading mechanisms; in particular, it assists us to locate CC cells in the potentially "vulnerable therapeutic areas" of the lymph nodes and lymph vessels.

Lymph-node positive cervical cancer is termed "locally advanced" irrespective of its FIGO stage. Indeed, FIGO in most recent publication, at the time of writing this paper, had not included lymph nodes in its staging system, despite LNM being a universally accepted prognostic factor and recognition that patients presenting with nodal disease require urgent treatment. Locally advanced cervical cancer (LACC) is a problematic condition in gynecologic oncology due to its heterogeneity, seriousness, and issues with the current treatment options [21].

Because progress in medical practice is now more rapid than the results of scientific research show, we decided the retrospective scope of our review should only be in a time frame of years 2010-2018 [22]. This view is also confirmed by the dissonance between the knowledge of mechanisms of LNM and the focus of ongoing studies.

However, the problematic issue in our study is the subjective selection of entry terms that may not emerge from basic research (selection bias). There is limited correlation between the results of imaging studies and the surgical staging of nodes $[23,24]$. Therefore, one of our initial criteria was a histopathologic confirmation of LNM.

Our manuscript reports data on completed clinical studies from April 2011 to April 2018, with a primary focus on novel therapies applied in patients with NPCC. Except for the study by Farley et al. [7], all the studies we selected involve targeted therapies. These studies can be further classified into distinct subtypes of a targeted approach, including, but not limited to: receptor-based therapy [10-12], disruption of metabolic pathways with the so-called "small molecules" $[8,12]$, inhibition of angiogenesis [12, 14], stimulation for apoptosis [9, 11-13], and combating cancer stem cells [9]. There is overlap in the mechanisms by which the treatment drugs function. The breakthrough in cancer treatment in recent years is thanks to the so-called immune checkpoint inhibitors.

\section{Angiogenesis inhibitors}

The first molecular targeting therapy introduced into the standard treatment of metastatic or recurrent CC was bevacizumab [22]. Bevacizumab is an anti-VEGF (vascular endothelial growth factor) monoclonal antibody which acts by targeting and inhibiting VEGF. It stops the tumor's ability to form new blood vessels through its disruption of the activation and proliferation of endothelial cells. In a phase III trial by the Gynecologic Oncology Group (GOG 240) the addition of bevacizumab to standard chemotherapy regi- 
mens (either cisplatin and paclitaxel, or, topotecan and paclitaxel) resulted in a prolonged median overall survival (OS) of 3.5 months, a median progression-free survival (PFS), and higher response rates [22]. The publication of the results of the GOG 240 trial not only changed the standard treatment for cervical cancer, but also opened a way for the introduction of other antiangiogenetic molecular inhibitors to clinical trials. In our analysis we identified two other clinical trials which used angiogenesis inhibitors $[12,14]$.

The first of these two mentioned above, the NCT00430781 phase II randomized trial, studied the use of pazopanib and lapatinib [12]. Pazopanib is a multi-target tyrosine kinase inhibitor (TKI) of the vascular endothelial growth factor receptor (VEGFR), the platelet-derived growth factor receptor (PDGFR), and the stem cell factor receptor (c-KIT). It had been previously approved for the treatment of advanced renal cell carcinoma and soft tissue sarcomas. Conversely, lapatinib is a TKI that inhibits the HER2/neu and epidermal growth factor receptor (EGFR) pathways. It is used in combination with other drugs in treating patients with breast cancer whose tumors overexpress HER2. The use of pazopanib in the study cited here was associated with improved OS and PFS and confirmed the efficacy of using antiangiogenetic agents for advanced and recurrent $\mathrm{CC}$.

The second study referred to above, the CIRCCa trial, investigated the use of cediranib in combination with chemotherapy in advanced and recurrent CC patients [14]. Cediranib is also a kinase inhibitor of VEGF. The addition of cediranib to carboplatin-paclitaxel chemotherapy (compared with the use of a placebo in the control group) resulted in higher response rates and a prolonged PFS. Unfortunately, the results were not statistically significant and the study was closed prematurely due to information from the manufacturers of cediranib about negative results in other studies using this agent [14].

\section{Receptor-based therapy agents}

Pembrolizumab, a major representative in this class of drugs, is a monoclonal antibody acting against programmed cell death protein 1 (PD-1), encoded by PDCD1 oncogene on locus 2q37.3. The PD-1 receptor is expressed on the cells of the immune system. Binding ligands to the PD-1 receptor inhibits the tumor-specific and cytotoxic activation of immune cells. Dendritic cells can induce T-cell development by targeting T lymphocytes through PD-L1 / PD-1 complex, increase T-cell tolerance to foreign antigens, or induce apoptosis of these cells. The efficacy of pembrolizumab in NPCC, among other cancers, was the subject of the large KEYONTE 028 study [10]. The study, Frenel et al., of patients treated with pembrolizumab, indicated a median duration of 5.4 months response for the four patients (17\%) who achieved a confirmed partial response [10]. These results encouraged the same researchers to commence another study with pembrolizumab. That ongoing KEYNOTE study (no. 826) is observing the effect of chemotherapy with pembrolizumab and compared with the use of a placebo in the control group in first line treatment for recurrent, persistent and metastatic cervical cancer.

Another receptor-based therapy agent, sunitinib, is a multi-targeted TKI. The tyrosine kinases family is involved in the growth of tumors, neoangiogenesis, and tumor metastasis disease. However, Mackay et al., observed no objective response in NPCC cases, despite a remarkable PFS (3.5 months). Fistula formation emerged as a major concern during CC therapy with sunitinib [11].

Pazopanib and lapatinib which are also TKIs, and are mentioned above, are mainly effective as antiangiogenetic drugs [12].

\section{Small-molecule therapies}

Triapine is a ribonucleotide reductase inhibitor that was proven to enhance cisplatin-radiation cytotoxicity. In the multimodal setting study by Kunos et al., the locoregional relapse rate for NPCC (Ib-Ila) and IIIb (FIGO 2009-2018) was $4 \%$, the DFS $80 \%$ and the OS $82 \%$ [8]. Pazopanib and lapatinib are also small-molecule therapies.

\section{Apoptosis stimulation}

Apoptosis stimulation is the active mechanism of several the above-mentioned therapeutic drugs [11, 12, 14]. Adoptive T-cell therapy is an autologous cancer-specific immunotherapy. A study by Stevanovic et al., showed that even a single transfer (infusion) of cancer-derived HPV-reactive T-cells (tumor infiltrating lymphocytes, TILs) causes the long-term cytotoxic effects of either complete or partial remission. ATC-based therapies are also examples of cancer stem cell blocking [9]. Pemetrexed, an antimetabolite and anti-folate, disrupts the metabolite replication mechanism. It was proven to be active as antitumor agent yielding a median PFS of 5.7 months, and a median OS of 12.3 months.

\section{Cancer stem cell blocking}

Adoptive T-cell therapy is used to target HPV-16 or HPV18 infected CC cells and therefore stimulate tumor regression in metastasis settings. This was proven in Stevanovic's et al. study of 9 patients, where 3 participants achieved an objective tumor response. In two of these (with adenocarcinoma), the objective response lasted 22 and 15 months, respectively [9].

\section{Novel targets}

Metastasis to the lymph nodes includes several mechanisms and factors which have potential as targets for new 
therapies (Tab. 3) [25]. The selected factors affecting the process of LNM and the possible candidates for further drug development are listed in Table 4 [26-33].

\section{Immunotherapy \\ - the future of anti-cancer therapy}

Regarding cancer progression and metastasis to the lymph nodes, the key issue is to understand and control the immune mechanisms that enable cancer survival.

Table 3. Overview of molecular mechanisms and factors contributing to lymph node metastasis [24]

\begin{tabular}{|l|l}
\hline \multirow{4}{*}{ Mechanisms } & - Loss of cell adhesion \\
& - Encreased cell mobility and invasiveness \\
& - Exit to the new tissue \\
& - Possible creation of distant metastases \\
\hline Factors & - Cytokines \\
& - Hormones \\
& - Adhesins \\
& - Matrix metalloproteinases
\end{tabular}

For many years, the role of the immune system in the development of cancer was the subject of hot disputes and controversy. Currently, many efforts are focused on finding the best strategies for combining the blocking effects of the CTLA-4 and PD-1 pathways, in combining immunotherapy with chemotherapy, and the application of small-molecule drug therapies, antineoplastic vaccines, and immunomodulatory agents.

Vaccines are a promising and novel type of drugs. A recent phase-IIB trial showed regression of high-grade CIN after the application of VGX-300, a vaccine containing two DNA plasmids encoding the E6 and E7 genes of HPV-16 and -18 [35]. This type of vaccine therapy induces the activation of the antigen presenting cell (APC) by three mechanisms: transfection of somatic cells (non-professional APC) with the antigen; direct transfection of professional APCs (both mediated by major histocompatibility complex, MHC I class molecules); and phagocytosis of transfected somatic cells by professional APCs (mediated by MHC II class molecules) to immunoreactive CD8+ and CD4+ T cells [36]. There is no evidence yet for the efficacy of a vaccine therapy against

Table 4. Selected factors affecting lymph node metastasis in cervical cancer [26-33]

\begin{tabular}{|c|c|c|}
\hline Factor & Its role & References \\
\hline $\begin{array}{l}\text { Lysosome- associated } \\
\text { membrane protein } \\
3 \text { (LAMP3) }\end{array}$ & $\begin{array}{l}\text { LAMPs are glycosylated proteins present predominantly on lysosome membrane, associated with } \\
\text { cancer progression and tumor spread. Additionally, LAMp3 is a molecular marker of mature dendritic } \\
\text { cells. Its expression is hypoxia regulated. LAMP3 overexpression in primary uterine cervical cancers } \\
\text { in comparison to normal uterine cervices was shown to be associated with increased metastatic } \\
\text { potential and with poorer prognosis. }\end{array}$ & $\begin{array}{l}\text { Nagelkerke at al. } \\
(2011)[26] \\
\text { Alesandrini et al. } \\
(2011)[27]\end{array}$ \\
\hline Wnt5A & $\begin{array}{l}\text { WNT proteins modulate the canonical ( } \beta \text {-catenin-dependent) and non-canonical ( } \beta \text {-catenin } \\
\text { independent) pathways and are involved in } \\
\text { in the regulation of cell growth, proliferation, survival, adhesion and migration. } \\
\text { Wnt } 5 \text { A promotes invasion and proliferation via receptor mediated endocytosis-dependent and } \\
\text { endocytosis-independent mechanisms, respectively. } \\
\text { Wnt5A-L ( } 337 \mathrm{AA} \text { ) isoform expression is down-, whereas Wnt5A-S (319AA) isoform is up-regulated in } \\
\text { cervix carcinoma in comparison with normal cervix. Wnt5A-L isoform inhibits, and Wnt5A-S isoform } \\
\text { promotes cervix carcinoma HeLa cell line proliferation. }\end{array}$ & $\begin{array}{l}\text { Lin et al. (2014) [28], } \\
\text { Shojima et al. (2015) } \\
\text { [29] }\end{array}$ \\
\hline miR-20a & $\begin{array}{l}\text { MicroRNAs are non-coding RNAs involved in the gene expression regulation via inhibition of } \\
\text { translation or degradation of target mRNA. } \\
\text { Mir-20a was shown to be up-regulated in cervical cancer tissue in comparison to normal } \\
\text { controls. Moreover, it was associated with lymph node metastases, tumor size, advanced stage } \\
\text { and advanced histological grade. In vitro inhibition of miR20a with anti-miR20a was associated with } \\
\text { decreased cell proliferation, migration and invasion. Moreover, anti-miR20a significantly suppressed } \\
\text { the growth of cervical cancer xenografts in nude mice. }\end{array}$ & Zhao et al. (2015) [30] \\
\hline miR-411 & $\begin{array}{l}\text { MiR-411 (targeting STAT-3 transcripts) was shown to be downregulated in cervical cancer tissue and } \\
\text { cell lines and correlated with tumor size, FIGO, lymph node - and distal metastasis. }\end{array}$ & Shan et al. (2018) [31] \\
\hline $\begin{array}{l}\text { Survivin, bcl-2 } \\
\text { and KAI1 }\end{array}$ & $\begin{array}{l}\text { Survivin and Bcl2 are tumor promoters via prevention of apoptosis, whereas KAI1 is a tumor } \\
\text { suppressor, promoting homotypic cell-cell adhesion } \\
\text { Survivin and Bcl2 protein levels were demonstrated to be significantly higher whereas KAl1 levels } \\
\text { were significantly lower in cervical cancer that in normal cervix, chronic cervicitis or CIN. Moreover, } \\
\text { survivin expression was positively and KAI1 - negatively associated with lymph node metastasis } \\
\text { and clinical stage. Bcl2 correlated positively with clinical stage but not with LNM. }\end{array}$ & $\begin{array}{l}\text { Zhou et al. (2015) [32], } \\
\text { Tsai and Weissman } \\
\text { (2015) [33] }\end{array}$ \\
\hline $\begin{array}{l}\text { Centrosomal protein } \\
55 \text { (CEP55) }\end{array}$ & $\begin{array}{l}\text { CEP55 is essential for cell division. The up- or downregulation can lead to the increased number of } \\
\text { multinucleated cells. } \\
\text { CEP55 expression was significantly elevated in cervical cancer tissue compared with adjacent } \\
\text { non-cancerous tissue and was associated with advanced tumor stage, lymph node metastasis and } \\
\text { poorer prognosis. }\end{array}$ & Qi et al. (2018) [34] \\
\hline
\end{tabular}


metastatic cervical cancer. However, systemic organ penetration and the action of immune cells speak for the potential effectiveness of such a vaccine, at least in a setting of maintenance therapy.

\section{CONCLUSIONS}

The results presented in this review are unsatisfactory but are encouraging for further research. Figure 2 sum- marizes the main available drugs currently used in cancer of the cervix with a molecular handle points in terms of lymph node metastasis formation. There are other, new drug groups that are not listed here, on the horizon: antifolate agents (except for pemetrexed), histone deacetylase inhibitors, mTOR inhibitors, protein kinase WEE1 inhibitors, Notch-signaling inhibitors, heat shock protein 90 interrupters, and poly ADP ribose inhibitors.

TUMOR PROGRESSION MECHANISMS

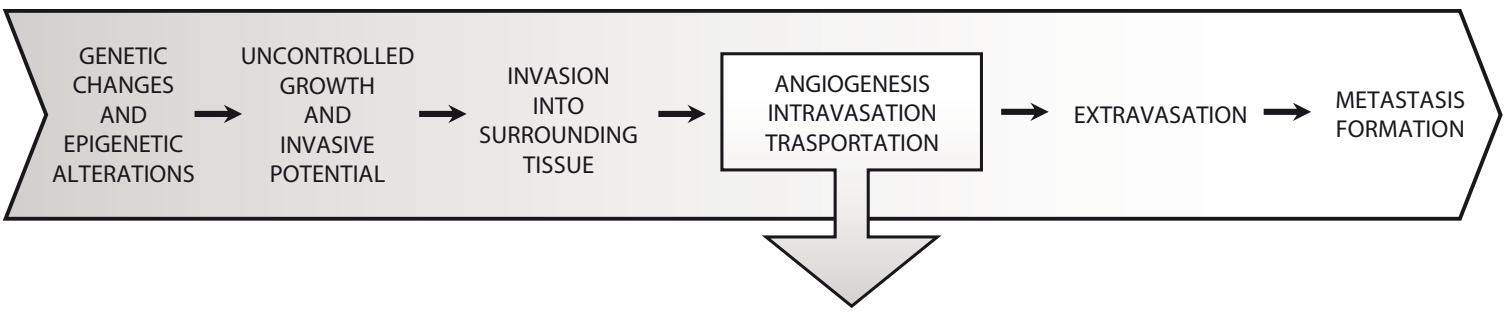

LN METASTASIS FORMATION MECHANISM

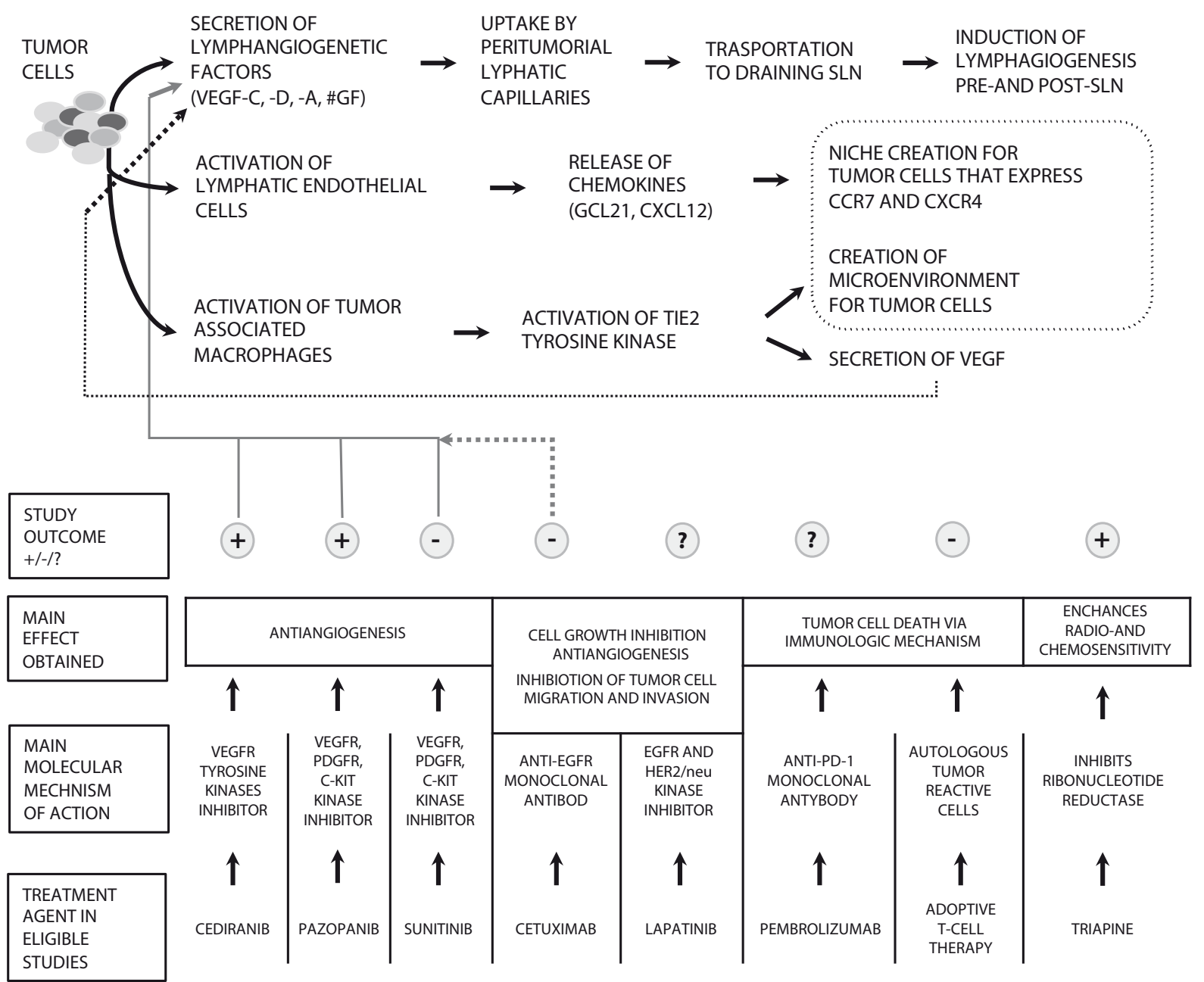

Figure 2. Tumor progression mechanisms and agents acting on these mechanisms in cervical cancer 
Currently, considering the limited number of studies and the various possible locations of lymph nodes metastases contributing to locally advanced uterine cervical cancer as a disease with a variety of prognoses and treatments, there are only a small number of management types available. In the first instance, all the current treatments involve biological approaches. Secondly, there are many possible targets, without counterpart, undergoing clinical trials. The delay between the concept and the drug availability of the drug therapy for preclinical baseline studies is counted in years. Added to this is the claim that fewer than $2 \%$ of preclinical studies transition to the clinical phase.

Finally, and consequently, it is worth noting that clinical practice is a fire-fighting intervention, instead being preventative. Nothing can cure cervical cancer metastases better than preventing them from occurring. Therefore, vaccination should be globally available and offered to all young women.

\section{Acknowledgments}

This review study received open access publishing costs from the Academic Association of Gynecologic Oncologists of Gdansk.

\section{Authors' contributions}

M.S. conceived, designed and wrote the major portion of the text. After the initial screening of available studies with key words by A.M., the literature search was critically evaluated by M.S. Further search for studies of interest that were cited in the references of our selected studies, as well as other studies selected from the subjective searches of the current authors, were also conducted (M.S., M.D., A.S.). M.O.V. contributed pathological insights on the topic. E.W. analyzed the data and conducted the statistical analysis regarding critical review of selected trials. P.P. gave some insight on cost of cervical cancer treatment and prophylaxis. D.K.M, M.L. and D.W. reviewed the article and contributed some important clinical notes and additions. All authors accepted the final version of the article.

\section{Conflict of interests}

The authors declare they have no conflicts of interest.

\section{REFERENCES}

1. Stoler M, Bergeron C, Colgan TJ, Ferenczy AS, Herrington CS, Kim KR, Loening T, Schneider A, Sherman ME, Wilbur DC, Wrigh T. Tumors of the uterine cervix. In: Kurman RJ, Carcangiu ML, Herrington CS, Young RH. ed. WHO Classification of Tumors of Female Reproductive Organs, 4th ed. WHO OMS, International Agency for Research on Cancer (IARC), Lyon 2014: 176.

2. Li X, Yin Y, Sheng X, et al. Distribution pattern of lymph node metastases and its implication in individualized radiotherapeutic clinical target volume delineation of regional lymph nodes in patients with stage IA to IIA cervical cancer. Radiat Oncol. 2015; 10: 40, doi: 10.1186/s13014015-0352-5, indexed in Pubmed: 25886535.
3. Pruefer FG, Lizarraga F, Maldonado V, et al. Participation of Om Htra2 serine-protease activity in the apoptosis induced by cisplatin on SW480 colon cancer cells. J Chemother. 2008; 20(3): 348-354, doi: $10.1179 /$ joc.2008.20.3.348, indexed in Pubmed: 18606591.

4. Fu KK. Biological basis for the interaction of chemotherapeutic agents and radiation therapy. Cancer. 1985; 55(9 Suppl): 2123-2130, indexed in Pubmed: 3884135.

5. National Comprehensive Cancer Network Guidelines: Cervical Cancer. Version 1.2018. https://www.nccn.org/professionals/physician_gls/pdf/cervical.pdf (28.04.2019).

6. STROBE. https://www.strobe-statement.org/index.php?id=strobe-ho me (28.04.2019).

7. Farley J, Sill MW, Birrer M, et al. Phase II study of cisplatin plus cetuximab in advanced, recurrent, and previously treated cancers of the cervix and evaluation of epidermal growth factor receptor immunohistochemical expression: a Gynecologic Oncology Group study. Gynecol Oncol. 2011; 121(2): 303-308, doi: 10.1016/.j.ygyno.2011.01.030, indexed in Pubmed: 21329967.

8. Kunos CA, SherertzTM. Long-Term Disease Control with Triapine-Based Radiochemotherapy for Patients with Stage IB2-IIIB Cervical Cancer. Front Oncol. 2014; 4: 184, doi: 10.3389/fonc.2014.00184, indexed in Pubmed: 25105092.

9. Stevanović S, Draper LM, Langhan MM, et al. Complete regression of metastatic cervical cancer after treatment with human papillomavirus-targeted tumor-infiltrating T cells. J Clin Oncol. 2015; 33(14): $1543-$ 1550, doi: 10.1200/JCO.2014.58.9093, indexed in Pubmed: 25823737.

10. Frenel JS, Le Tourneau C, O'Neil B, et al. Safety and Efficacy of Pembrolizumab in Advanced, Programmed Death Ligand 1-Positive Cervical Cancer: Results From the Phase Ib KEYNOTE-028 Trial. J Clin Oncol. 2017; 35(36): 4035-4041, doi: 10.1200/JCO.2017.74.5471, indexed in Pubmed: 29095678.

11. Mackay HJ, Tinker A, Winquist $E$, et al. A phase II study of sunitinib in patients with locally advanced or metastatic cervical carcinoma: $\mathrm{NCIC}$ CTG Trial IND.184. Gynecol Oncol. 2010; 116(2): 163-167, doi: 10.1016/j. ygyno.2009.08.012, indexed in Pubmed: 19740535.

12. Monk BJ, Pandite LN. Survival data from a phase II, open-label study of pazopanib or lapatinib monotherapy in patients with advanced and recurrent cervical cancer. J Clin Oncol. 2011; 29(36): 4845.

13. Miller D, Blessing J, Ramondetta L, et al. Pemetrexed and Cisplatin for the Treatment of Advanced, Persistent, or Recurrent Carcinoma of the Cervix: A Limited Access Phase II Trial of the Gynecologic Oncology Group. J Clin Oncol. 2014; 32(25): 2744-2749, doi: 10.1200/jco.2013.54.7448.

14. Symonds RP, Gourley C, Davidson S, et al. Cediranib combined with carboplatin and paclitaxel in patients with metastatic or recurrent cervical cancer (CIRCCa): a randomised, double-blind, placebo-controlled phase 2 trial. Lancet Oncol. 2015; 16(15): 1515-1524, doi: 10.1016/S1470-2045(15)00220-X, indexed in Pubmed: 26474517.

15. Stoler M, Bergeron $C$, Colgan TJ, Ferenczy AS, Herrington CS, Kim KR, Loening T, Schneider A, Sherman ME, Wilbur DC, Wrigh T. Tumors of the uterine cervix. In: Kurman RJ, Carcangiu ML, Herrington CS, Young RH. ed. WHO Classification of Tumors of Female Reproductive Organs, 4th ed. WHO OMS, International Agency for Research on Cancer (IARC), Lyon 2014: 172-181.

16. Bahnassy AA, Zekri AR, Saleh $M$, et al. The possible role of cell cycle regulators in multistep process of $\mathrm{HPV}$-associated cervical carcinoma. BMC Clin Pathol. 2007; 7: 4, doi: 10.1186/1472-6890-7-4, indexed in Pubmed: 17521451.

17. Tan SC, Ankathil R. Genetic susceptibility to cervical cancer: role of common polymorphisms in apoptosis-related genes. Tumour Biol. 2015; 36(9): 6633-6644, doi: 10.1007/s13277-015-3868-2, indexed in Pubmed: 26242271.

18. Höckel M, Horn LC, Tetsch E, et al. Pattern analysis of regional spread and therapeutic lymph node dissection in cervical cancer based on ontogenetic anatomy. Gynecol Oncol. 2012; 125(1): 168-174, doi: 10.1016/j. ygyno.2011.12.419, indexed in Pubmed: 22155677.

19. Li X, Yin Y, Sheng $X$, et al. Distribution pattern of lymph node metastases and its implication in individualized radiotherapeutic clinical target volume delineation of regional lymph nodes in patients with stage IA to IIA cervical cancer. Radiat Oncol. 2015; 10: 40, doi: 10.1186/s13014015-0352-5, indexed in Pubmed: 25886535.

20. Fehm T, Banys $M$, Rack $B$, et al. Presence of disseminated tumor cells in bone marrow correlates with tumor stage and nodal involvement in cervical cancer patients. Int J Cancer. 2014; 134(4): 925-931, doi: 10.1002/ijc.28417, indexed in Pubmed: 23921989. 
21. Liu Z, Hu Ke, Liu An, et al. Patterns of lymph node metastasis in locally advanced cervical cancer. Medicine (Baltimore). 2016; 95(39): e4814, doi: 10.1097/MD.0000000000004814, indexed in Pubmed: 27684810.

22. Tewari KS, Sill MW, Penson RT, et al. Bevacizumab for advanced cervical cancer: final overall survival and adverse event analysis of a randomised, controlled, open-label, phase 3 trial (Gynecologic Oncology Group 240). Lancet. 2017; 390(10103): 1654-1663, doi: 10.1016/S01406736(17)31607-0, indexed in Pubmed: 28756902.

23. Frumovitz M, Querleu D, Gil-Moreno A, et al. Lymphadenectomy in locally advanced cervical cancer study (LiLACS): Phase III clinical trial comparing surgical with radiologic staging in patients with stages IB2-IVA cervical cancer. J Minim Invasive Gynecol. 2014; 21(1): 3-8, doi: 10.1016/j. imiq.2013.07.007, indexed in Pubmed: 23911560.

24. Vandeperre $A$, Van Limbergen $E$, Leunen $K$, et al. Para-aortic lymph node metastases in locally advanced cervical cancer: Comparison between surgical staging and imaging. Gynecol Oncol. 2015; 138(2): 299-303, doi: 10.1016/i.ygyno.2015.05.021, indexed in Pubmed: 26007204.

25. Zhang Li, Hao Q, Bao L, et al. Phenethyl isothiocyanate suppresses cervical carcinoma metastasis potential and its molecular mechanism. Mol Med Rep. 2014; 10(5): 2675-2680, doi: 10.3892/mmr.2014.2565, indexed in Pubmed: 25215638.

26. Nagelkerke A, Mujcic H, Bussink J, et al. Hypoxic regulation and prognostic value of LAMP3 expression in breast cancer. Cancer. 2011; 117(16): 3670-3681, doi: 10.1002/cncr.25938, indexed in Pubmed: 21319150.

27. Alessandrini F, Pezzè L, Ciribilli Y. LAMPs: Shedding light on cancer biology. Semin Oncol. 2017; 44(4): 239-253, doi: 10.1053/j.seminoncol.2017.10.013, indexed in Pubmed: 29526252.

28. Lin Li, LiuY, Zhao W, et al. Wnt5A expression is associated with the tumor metastasis and clinical survival in cervical cancer. Int J Clin Exp Pathol. 2014; 7(9): 6072-6078, indexed in Pubmed: 25337253.
29. Shojima K, Sato A, Hanaki H, et al. Wnt5a promotes cancer cell invasion and proliferation by receptor-mediated endocytosis-dependent and -independent mechanisms, respectively. Sci Rep. 2015; 5: 8042, doi: $10.1038 /$ srep08042, indexed in Pubmed: 25622531.

30. Zhao S, Yao D, Chen J, et al. MiR-20a promotes cervical cancer proliferation and metastasis in vitro and in vivo. PLoS One. 2015; 10(3): e0120905, doi: 10.1371 /journal.pone.0120905, indexed in Pubmed: 25803820.

31. Shan D, Shang Y, Hu T. MicroRNA-411 Inhibits Cervical Cancer Progression by Directly Targeting STAT3. Oncol Res. 2019; 27(3): 349-358, doi: 10.3727/096504018X15247361080118, indexed in Pubmed: 29716674.

32. Zhou XL, Wang M. Expression levels of survivin, BCl-2, and KAl1 proteins in cervical cancer and their correlation with metastasis. Genet Mol Res. 2015; 14(4): 17059-17067, doi: 10.4238/2015.December.16.6, indexed in Pubmed: 26681053.

33. Tsai YC, Weissman AM. Dissecting the diverse functions of the metastasis suppressor CD82/KAI1. FEBS Lett. 2011; 585(20): 3166-3173, doi: 10.1016/i.febslet.2011.08.031, indexed in Pubmed: 21875585.

34. Qi J, Liu G, Wang F. High levels of centrosomal protein 55 expression is associated with poor clinical prognosis in patients with cervical cancer. Oncol Lett. 2018; 15(6): 9347-9352, doi: 10.3892/ol.2018.8448, indexed in Pubmed: 29805659.

35. Trimble CL, Morrow MP, Kraynyak KA, et al. Safety, efficacy, and immunogenicity of VGX-3100, a therapeutic synthetic DNA vaccine targeting human papillomavirus 16 and $18 \mathrm{E} 6$ and $\mathrm{E} 7$ proteins for cervical intraepithelial neoplasia 2/3: a randomised, double-blind, placebo-controlled phase 2 b trial. Lancet. 2015; 386(10008): 2078-2088, doi: 10.1016/S01406736(15)00239-1, indexed in Pubmed: 26386540.

36. Hancock G, Hellner K, Dorrell L. Therapeutic HPV vaccines. Best Pract Res Clin Obstet Gynaecol. 2018; 47: 59-72, doi: 10.1016/i.bpobgyn.2017.09.008, indexed in Pubmed: 29108943. 